\title{
Quantification of Acetylated Tubulin
}

\author{
María E. Chesta ${ }^{1}$, Agustín Carbajal $^{1}$, C. Gastón Bisig, Carlos A. Arce*
}

Centro de Investigaciones en Química Biológica de Córdoba (CIQUIBIC), UNC-CONICET, Departamento de Química Biológica, Facultad de Ciencias Químicas, Universidad Nacional de Córdoba, 5000-Córdoba, Argentina

${ }^{1}$ These authors contributed equally to this study.

*Address correspondence to: Carlos A. Arce, Departamento de Química Biológica, Facultad de Ciencias Químicas, Universidad Nacional de Córdoba, 5000-Córdoba, Argentina. E-mail: caecra@dqb.fcq.unc.edu.ar.

Running title: Quantification of AcTubulin

Abbreviations used: AcTubulin, acetylated tubulin; mAb, monoclonal antibody; TSA, Trichostatin A

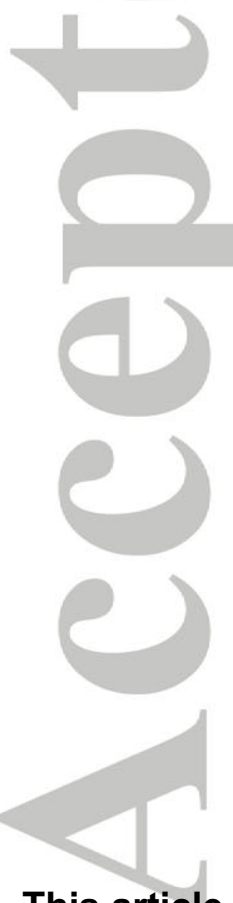

This article has been accepted for publication and undergone full peer review but has not been through the copyediting, typesetting, pagination and proofreading process which may lead to differences between this version and the Version of Record. Please cite this article as Chesta, et al., (2013), Q uantification of A cetylated Tubulin . 


\section{Abstract}

The acetylation/deacetylation of $\mathrm{Lys}^{40}$ of the $\alpha$-subunit is an important post-translational modification undergone by tubulin during the life of a cell. Many previous studies have addressed the physiological role of this acetylation process using various approaches based on changes of acetylated tubulin (AcTubulin) content. In most of these studies, however, the actual amounts of AcTubulin were not known and it was difficult to draw conclusions. We present here a simple method to estimate the percentage of AcTubulin relative to total tubulin. The method is based on acetylation of the tubulin sample with acetic anhydride, Western blotting stained by anti-AcTubulin antibody, and comparison of the optical density of the AcTubulin band with that of a corresponding sample that was not chemically acetylated.

Key words: acetylated tubulin, microtubules, quantification method, chemical acetylation

\section{Introduction}

Microtubules are dynamic fibrous structures present in the cytoplasm of all eukaryotic cells. The main constituent protein of microtubules, tubulin, is subject to many post-translational modifications including acetylation/deacetylation, tyrosination/detyrosination, polyglutamylation, polyglycylation, and phosphorylation [Janke and Bulinski, 2011]. The functional roles of these tubulin modifications have not been precisely defined in spite of intensive studies. It is increasingly clear that acetylation of tubulin plays an important role in various cell functions including cell migration, division, and differentiation [Perdiz et al., 2011], although conflicting results have been obtained in some studies. Our previous studies have shown that acetylated tubulin (AcTubulin)is specifically associated with $\mathrm{Na}^{+}, \mathrm{K}^{+}$-ATPase (the sodium pump) in membranes of neural and nonneural cells and that this association results in inhibition of the ATPase activity [Alonso et al., 1998; Casale et al., 2001; Casale et al., 2003; Casale et al., 2005; Santander et al., 2006; Zampar et al., 2009]. Specific acetylation catalyzed by MEC-17 occurs on the $\varepsilon-\mathrm{NH}_{2}$ group of Lys ${ }^{40}$ of the $\alpha-$ tubulin chain [Akella et al., 2010; Shida et al., 2010], and the acetyl group can be removed by NAD-dependent Sirtuin2 (Sirt2, an analog of yeast Sir2) [North et al., 2003] and by cytoplasmic histone deacetylase 6 (HDAC6) [Hubbert et al., 2002; Zhang et al., 2003]. The acetyl group can also be added to $\mathrm{Lys}^{40}$ (and to other reactive amino acid residues of tubulin and of contaminant proteins) by chemical acetylation with acetic anhydride [Piperno and Fuller, 1985]. To avoid nomenclatural confusion, we use the term "AcTubulin" in this paper to refer to tubulin that contains an acetyl group bound to the $\varepsilon-\mathrm{NH}_{2}$ of $L y s^{40}$ of the $\alpha$-chain and "chemically acetylated tubulin" to refer to tubulin in which acetyl groups are bound nonspecifically to not only Lys ${ }^{40}$ but also other Lys 
residues and other sites that can be acetylated. The monoclonal antibody (mAb) 6-11B-1 is specific to the acetylatedLys ${ }^{40}$ of $\alpha$-tubulin [Piperno and Fuller, 1985] and can therefore be used to distinguish this epitope from all acetyl groups bound to other sites on $\alpha$-tubulin as a result of chemical acetylation. In most published studies regarding the role of tubulin acetylation, conclusions have been drawn on the basis of cell behavior following an increase or decrease in the amount of AcTubulin in cultured cells by inhibiting/silencing or overexpressing the acetylating or deacetylating enzymes [Hubbert et al., 2002; Li et al., 2012; Tran et al., 2007]. The amount of AcTubulin in cultured cells is generally very low. Even when treatment with Sirt2 or HDAC6 inhibitors produces a seemingly large increase of AcTubulin as visualized by immunofluorescence microscopy or Western blotting, the resulting amounts of AcTubulin relative to total tubulin are uncertain. In most biochemical experiments using partially purified tubulin, the investigators have not taken into account the proportion of tubulin molecules that are acetylated on Lys ${ }^{40}$ of $\alpha$-tubulin with respect to total tubulin. We must therefore be cautious in drawing conclusions from this type of experiment. Data regarding the amount of AcTubulin in each experimental system are essential for designing protocols and for drawing reliable conclusions. Conclusions or assumptions from cellular and molecular experiments should be corroborated using biochemical systems with purified proteins. We recently described a method for purifying tubulin with a high acetylated isotype content from rat brain and determined that approximately $64 \%$ of such tubulin molecules are acetylated [Carbajal et al., 2013]. We now describe a simple method to estimate the amount of AcTubulin as a percentage of total tubulin. This method can be used to quantify AcTubulin in purified tubulin preparations or in crude extracts from cells.

\section{Materials and Methods}

\section{Chemicals}

MES (2-(N-morpholino)ethanesulfonic acid), TSA (Trichostatin A), Taxol, Triton X-100, BSA (bovine serum albumin), SDS, EGTA, PMSF, phenanthroline, mouse mAb 6-11B-1 specific for AcTubulin, culture media and antibiotics were from Sigma-Aldrich (St. Louis, MO, USA). IRDye $800 \mathrm{CW}$ goat anti-mouse IgG was from Li-Cor Biosciences (Lincoln, NE, USA). Recombinant Protein G-Sepharose 4B conjugate was from Invitrogen Corp. (Grand Island, NY, USA) and Alexa Fluor 488 Donkey Anti-Mouse lgG $\left(\mathrm{H}_{+} \mathrm{L}\right)$ was from Santa Cruz Biotechnology Inc. (Santa Cruz, CA, USA). FluorSave reagent was from Calbiochem/ EMD Biosciences (La Jolla, CA, USA). Fetal bovine serum was from Natocor (Córdoba, Argentina). Boric acid was from PlusOne, Pharmacia Biotech (Uppsala, Sweden). Acetic anhydride was from J. T. Baker (Phillipsburg, NJ, USA). 


\section{Cells}

CAD cells (a subclone of a catecholaminergic cell line derived from a mouse neuronal brain tumor) were cultured in DMEM/F12 (Dulbecco's modified Eagle's medium/Ham's F12). CHO (Chinese Hamster Ovary) and COS cells were grown in DMEM. All cell lines were cultured in their respective media supplemented with $10 \%$ (v/v) FBS, 10 units $/ \mathrm{ml}$ penicillin, and $100 \mu \mathrm{g} / \mathrm{ml}$ streptomycin and maintained at $37^{\circ} \mathrm{C}$ in an air/ $\mathrm{CO}_{2}(19: 1)$ atmosphere with high humidity.

\section{Purification of microtubule protein depleted or enriched in AcTubulin}

Purification of two tubulin preparations was performed as described previously [Carbajal et al., 2013]. The same protocol was used for purification of tubulin depleted or enriched in the acetylated isotype except that TSA, an HDAC6 inhibitor, was added to the buffers for the AcTubulin-enriched preparation and absent for the AcTubulin-depleted preparation. Briefly, Wistar rat brains were homogenized in 1.5 volumes of cold $\left(0^{\circ} \mathrm{C}\right)$ MEM buffer (100 mM MES buffer, pH 6.7, containing 1 $\mathrm{mM}$ EGTA, $1 \mathrm{mM} \mathrm{MgCl} 2,1 \mathrm{mM}$ PMSF, and $1 \mathrm{mM}$ phenanthroline) supplemented with $5 \mu \mathrm{M}$ TSA for the AcTubulin-enriched preparation and centrifuged at $100,000 \times g$ for $30 \mathrm{~min}$ at $4{ }^{\circ} \mathrm{C}$. The supernatant fraction (termed $\mathrm{SN}_{1}$ ) was added with glycerol (final concentration $40 \%$ ) and incubated at $37^{\circ} \mathrm{C}$ for $30 \mathrm{~min}$. The mixture was centrifuged at $100,000 \times \mathrm{g}$ for $30 \mathrm{~min}$ at $27^{\circ} \mathrm{C}$, and the supernatant $\left(\mathrm{SN}_{2}\right)$ and sedimented microtubules $\left(\mathrm{P}_{2}\right)$ were separated. The microtubules were resuspended in cold MEM buffer (1/5 of the original volume) containing $1 \mu \mathrm{M}$ TSA for the AcTubulin-enriched preparation, kept at $0 \stackrel{\circ}{ } \mathrm{C}$ for $30 \mathrm{~min}$, and centrifuged at $100,000 \times \mathrm{g}$ for $30 \mathrm{~min}$ at $4{ }^{\circ} \mathrm{C}$. The supernatant $\left(\mathrm{SN}_{3}\right.$; microtubule protein purified by one cycle) was collected.

Animal handling was performed according to the Guide to the Care and Use of Experimental Animals published by the Canadian Council on Animal Care and approved by the local animal care committee (Faculty of Chemistry, Universidad Nacional de Córdoba, Argentina).

\section{Immunopurification of AcTubulin}

Anti-AcTubulin mAb 6-11B-1 was linked to Protein G-Sepharose beads (100 $\mu \mathrm{g}$ IgG: $200 \mu \mathrm{l}$ beads) following the manufacturer's instructions. The 6-11B-1-linked beads were mixed with $600 \mu \mathrm{l}$ $(1.5 \mathrm{mg} / \mathrm{ml})$ of an AcTubulin-enriched preparation $\left(\mathrm{SN}_{3}\right)$, incubated for $2 \mathrm{~h}$ at room temperature and washed 5 times with 10 bed volumes of PBS supplemented with $0.5 \%$ Triton X-100. Bound proteins were eluted twice by mild agitation for $5 \mathrm{~min}$ at room temperature with $400 \mu \mathrm{l}$ of $100 \mathrm{mM}$ sodium carbonate buffer, $\mathrm{pH} 12$, containing $9 \mu \mathrm{M}$ TSA. The two eluted fractions were combined and stored at $-20^{\circ} \mathrm{C}$. As a control, 6-11B-1-linked beads were incubated with an AcTubulindepleted preparation and processed in the same way.

\section{SDS-PAGE and Western blotting}


Proteins were separated by SDS-PAGE (10\% gels) [Laemmli, 1970] and transferred to nitrocellulose sheets [Towbin et al., 1979]. The sheets were incubated with primary antibody for $4 \mathrm{~h}$ at room temperature (anti-AcTubulin: 1:5,000 dilution; 1\% non-fat milk in PBS as blocking medium), washed, incubated with infrared fluorescent secondary antibody for $1 \mathrm{~h}$ at room temperature (1:25,000 dilution; blocking medium as above), washed, and scanned by an Odyssey infrared scanner (Li-Cor). Bands were quantified using the Scion Image software program (Scion Corporation; Frederick, Maryland, USA).

\section{Immunofluorescence}

Cells were cultured on coverslips and fixed with anhydrous methanol at $-20{ }^{\circ} \mathrm{C}$ for $10 \mathrm{~min}$. The samples were washed with PBS, incubated with $5 \%(\mathrm{w} / \mathrm{v}) \mathrm{BSA}$ in PBS for $1 \mathrm{~h}$, and incubated with the primary antibody (anti-AcTubulin mAb 6-11-B1, 1:1,000 dilution; 1\% BSA in PBS as blocking medium) for $4 \mathrm{~h}$ at $37^{\circ} \mathrm{C}$. The cells were washed 3 times with PBS, incubated for $1 \mathrm{~h}$ at $37^{\circ} \mathrm{C}$ with secondary antibody (anti-mouse IgG-Alexa ${ }^{488}$ diluted 1:1000), washed 3 times with PBS, and the coverslips were mounted in FluorSave reagent. Images were collected using an FV1000 Olympus confocal spectral microscope (Olympus Latin America, Miami, FL, USA) equipped with an argon/helium/neon laser at the appropriate wavelength and the software (Olympus FV Viewer) provided by the manufacturer, and processed using the Image J program 1.46r (Wayne Rasband; $\mathrm{NIH}$, USA).

\section{Chemical acetylation of tubulin}

Partially purified preparations:A $100-\mu$ l sample of $\mathrm{SN}_{1}(15 \mathrm{mg} / \mathrm{ml}$ protein) or of a microtubule protein preparation purified by one cycle $(2-4 \mathrm{mg} / \mathrm{ml}$ protein) was mixed with $125 \mu \mathrm{l}$ of boric acid $(500 \mathrm{mM}, \mathrm{pH} 9)$ and then with $50 \mu \mathrm{l}$ of $1 \%(\mathrm{v} / \mathrm{v})$ freshly prepared cold acetic anhydride. After incubation at $4 \stackrel{\circ}{\circ} \mathrm{C}$ for $20 \mathrm{~min}, 100 \mu \mathrm{l}$ of $5 \mathrm{x}$ Laemmli sample buffer was added. The samples were diluted with $1 \mathrm{x}$ Laemmli sample buffer to obtain tubulin concentrations adequate for SDS-PAGE and Western blotting. Two samples (containing $1 x$ and $2 x$ tubulin amounts) of each sample were electrophoresed in triplicate. A control (non-acetylated) sample in which acetic anhydride was substituted by distilled water was processed in parallel.

Cell extracts: Cells from a 10-cm diameter culture dish (80\% confluence) were washed with 10 $\mathrm{ml}$ of warm $\left(37^{\circ} \mathrm{C}\right)$ PBS and harvested in $2 \mathrm{ml}$ of ext raction buffer ( $280 \mathrm{mM}$ boric acid, $\mathrm{pH} 9,1 \%$ SDS, $3 \mu \mathrm{M}$ TSA, $1 \mathrm{mM}$ PMSF, and $1 \mathrm{mM}$ EGTA). The cell extract was sonicated 3 times for $30 \mathrm{sec}$ at position 40 in a Cole Parmer Ultrasonic Homogenizer and centrifuged at 10,000 x g for $10 \mathrm{~min}$ at $15 \mathrm{C}$. The supernatant fraction was collected and d ivided into 2 fractions of $900 \mu \mathrm{l}$ each. One fraction was added with $110 \mu \mathrm{l}$ of water and the other with $110 \mu \mathrm{l}$ of $2 \%(\mathrm{v} / \mathrm{v})$ freshly prepared acetic anhydride. Both aliquots were kept at $4{ }^{\circ} \mathrm{C}$ or $20 \mathrm{~min}$ and then subjected to protein 
precipitation with methanol-chloroform (see following section). Protein pellets were resuspended in $300 \mu \mathrm{l}$ of Laemmli sample buffer with 5\% 2-mercaptoethanol and sonicated 3 times for 30 sec.

Aliquots (approximately $20 \mu \mathrm{l}$ ) of each preparation were subjected (in triplicate) to Western blotting with mAb 6-11B-1 to analyze AcTubulin.

\section{Methanol-chloroform protein precipitation}

The method of Wessel and Flügge [1984] was used. Briefly, 1 volume of aqueous protein solution was mixed with 1.25 volumes of methanol-chloroform $(4: 1)$ by vortexing for approximately $30 \mathrm{sec}$. The mixture was centrifuged at $10,000 \times \mathrm{g}$ for $10 \mathrm{~min}$ at room temperature, and the upper phase was carefully removed without removing the interphase. Methanol $(0.75$ volumes relative to the original volume) was added, and the mixture was centrifuged at $10,000 \times g$ at room temperature for $10 \mathrm{~min}$. The solvent was removed, and the pellet was dried at room temperature and then resuspended in Laemmli sample buffer and sonicated.

\section{Protein measurement}

Protein content was measured by the method of Bradford (1976) using bovine serum albumin as the standard.

\section{Results and Discussion}

\section{The basic concept of the method}

The method described here is based on the increase in the amount ofAcTubulin produced by chemical acetylation of a tubulin sample relative to that of an identical amount of non-treated sample, assuming that Lys ${ }^{40}$ of $\alpha$-tubulin is $100 \%$ acetylated by the procedure. A sample of the tubulin preparation to be analyzed is extensively acetylated with acetic anhydride in a one-step procedure and then subjected to Western blotting and staining with specific anti-AcTubulin mAb 611B-1("chemically acetylated"). A sample containing an identical amount of protein is processed in the same way but with substitution of acetic anhydride by vehicle ("non-chemically acetylated"). It should be noted that the non-chemically acetylated sample may contain a certain amount of endogenous acetylated tubulin. The optical densities (O.D.) of the AcTubulin bands are determined. The percentage of AcTubulin relative to total tubulin is calculated by the following formula:

$\%$ AcTubulin $=$ (O.D. non-chemically acetylated / O.D. chemically acetylated $) \times 100 \%$ 
This formula is applicable provided that: (i) the optical density valuesare directly proportional to the protein amounts; (ii) identical amounts of total tubulin in the "acetylated" and "non-acetylated" samples are compared. To satisfy these criteria, identical volumes of the two samples must be processed in parallel.

\section{Conditions for maximal tubulin acetylation on $\mathrm{Lys}^{40}$ of the $\alpha$-subunit}

Chemical acetylation of a crude rat brain preparation $\left(\mathrm{SN}_{1}\right.$, obtained in the absence of TSA) resulted in a large increase of AcTubulin as assessed by Western blotting with specific mAb 6-11B1 (Fig. 1A). A slight decrease in the electrophoretic mobility of the chemically acetylated tubulin band was observed. This decrease may have resulted from an alteration in the molecular weight and/or spatial structure of the tubulin molecule and/or in the affinity for SDS induced by acetylation of protein sites other than $\mathrm{Lys}^{40}$ of $\alpha$-tubulin. The effect of chemical acetylation on an AcTubulin preparation considered to be $100 \%$ acetylated because it was immunopurified from an AcTubulinenriched preparation is shown in Fig. $1 \mathrm{~A}$ (right panel). A similar shift in the electrophoretic mobility was more clearly observed. Chemical acetylation did not significantly increase the intensity of the immunopurified tubulin sample. This finding suggests that chemical acetylation does not significantly interfere with the affinity of mAb 6-11B-1. The fact that in both cases (with $\mathrm{SN}_{1}$ and with immunopurified tubulin) the shift in electrophoretic mobility affected most (perhaps all) of the tubulin molecules suggests that the acetylation was complete. To confirm that a single acetylation step was sufficient to acetylate $100 \%$ of $\mathrm{Lys}^{40}$, a SN 1 preparation (obtained in the absence of TSA) was subjected to chemical acetylation 1,2, and 3 times. Following the analysis of various amounts of protein by Western blotting, no significant increase in AcTubulin content was observed (Fig. 1B) when this procedure was repeated once or twice on a tubulin sample that was previously chemically acetylated. This finding was confirmed statistically (Fig. 1C). Taken together, these results indicate that one cycle of chemical acetylation under the conditions described is sufficient for extensive and maximal acetylation of $\mathrm{Lys}^{40}$ of the $\alpha$-chain of tubulin.

Because chemical acetylation is nonspecific, we considered the possibility that the reaction generated new epitopes in the tubulin molecule that were recognized by mAb 6-11B-1. However, following acetylation of a crude soluble brain extract $\left(\mathrm{SN}_{1}\right)$ in which more than $84 \%$ of the proteins were contaminants of tubulin (Fig. 2A), approximately $94 \%$ of the $6-11 \mathrm{~B}-1$ staining coincided with the tubulin band (Fig. 2B) and the remaining $6 \%$ with other protein bands, indicating a very low probability that chemical acetylation could generate new epitopes recognized by $6-11 \mathrm{~B}-1$ in sites other than $\mathrm{Lys}^{40}$. This finding is consistent with the observation that chemical acetylation of a $100 \%$ pure AcTubulin sample did not increase the intensity of the AcTubulin band (Fig. 1A, right panel). We conclude that most (perhaps all) of the staining of the tubulin band following chemical acetylation was due to the reactivity of the acetyl group on Lys ${ }^{40}$ of the $\alpha$-subunit. 


\section{Factors that might alter the basic concept of the method}

After chemical acetylation and subsequent SDS-PAGE and staining with Coomassie Blue, we observed a lower intensity in the staining that coincided with the tubulin band, in comparison with an equivalent aliquot of the non-acetylated sample. This finding was surprising because we loaded equal amounts of acetylated and non-acetylated samples. This observation was presumed to reflect a staining artifact rather than an actual loss of tubulin because silver staining did not reveal such a difference. This conclusion was supported by the finding that after nitrocellulose blotting and staining with an anti-Glu-tubulin antibody the optical densities of the two samples were identical (results not shown). These are important controls because the method is based on the comparison of equal amounts of total tubulin before and after chemical acetylation. We presume that the above difference was due to a lower affinity of Coomassie Blue for proteins whose structures were altered by the incorporation of acetyl groups in several sites.

The determination of the amount of AcTubulin relative to total tubulin is dependent on the optical density of the AcTubulin band (as detected using mAb 6-11B-1) before vs. after chemical acetylation. It was therefore important to determine whether the optical density values were directly proportional to the AcTubulin amounts and to determine the range of linearity. This function was linear up to $0.8 \mu \mathrm{g}$ protein (equivalent to approximately $440 \mathrm{ng}$ AcTubulin because in this preparation tubulin accounts for approximately $55 \%$ of total protein) (Fig. 3 ). When this method is applied to unknown samples, it is therefore convenient to load various amounts of the samples for the corresponding Western blot analysis and to use data collected within the linear range.

\section{Experimental validation of the method}

To test the accuracy of the method, we prepared 3 tubulin preparations with known AcTubulin concentrations and applied the chemical acetylation procedure to determine experimentally the AcTubulin concentration in each preparation. The AcTubulin standards were prepared by mixing different proportions of an AcTubulin-enriched preparation ( $\mathrm{SN}_{3}$, obtained in the presence of TSA) that contained $64 \%$ AcTubulin with another tubulin preparation (of the same concentration) lacking the acetylated isotype [Carbajal et al., 2013]. The 3 AcTubulin standards contained 7.5, 27.5, and $60 \%$ AcTubulin, respectively. The AcTubulin amounts determined by our method were in good agreement (within 10\% standard error) with the values corresponding to the standards (Fig. 4). The method is therefore useful for estimation of the percentage of acetylated tubulin molecules relative to total tubulin.

\section{Quantification of AcTubulin in cultured cells}

The measurement of AcTubulin content in cultured cells using the chemical acetylation method requires the use of buffers containing SDS or Triton X-100 to dissolve the cells and, in 
some cases, to isolate the soluble and cytoskeletal fractions. We examined the effects of these detergents on the degree of acetylation obtained by chemical acetylation of a crude soluble rat brain preparation $\left(\mathrm{SN}_{1}\right.$, obtained in the absence of TSA). Various amounts of the detergents were mixed with the tubulin preparation, and the mixtures were subjected to chemical acetylation and subsequent Western blot analysis and staining with mAb 6-11B-1. No differences in the optical densities of tubulin bands were observed among any of the detergent samples or the sample without detergent (Fig. 5A). This finding indicates that the SDS or Triton X-100 used to dissolve cultured cells did not interfere with our quantification method. We then applied the method to estimate the amount of AcTubulin in 3 cell types treated or not with TSA. The AcTubulin content in non-treated cells was generally very low (Fig. 5B). The effect of TSA treatment was variable depending on the cell type. The AcTubulin content increased approximately 4-fold in $\mathrm{CHO}$ cells and approximately 20 -fold in COS cells. CAD cells showed a very low (or zero) AcTubulin content, and this content increased to $25 \%$ of total tubulin after TSA treatment. A comparison of immunofluorescence images revealed with anti-AcTubulin of similarly treated vs. non-treated cells (Fig. 5C) showed a general consistency with Western blot values (Fig. 5B). Taxol is another wellknown compound that induces an increase in the amount of acetylated microtubules in living cells because of its microtubule-stabilizing effect. A further experiment showed that the increase of AcTubulin in $\mathrm{CHO}$ and COS cells induced by taxol after 2 and $6 \mathrm{~h}$ of treatment and visualized by immunofluorescence microscopy (Fig. 6A), although less than the increase produced by TSA, could be detected and quantified by the chemical acetylation method (Fig.6B).

These findings indicate that our method is sufficiently sensitive to detect modest variations of AcTubulin content in cells. This quantification method, in combination with immunofluorescence microscopy, will be useful for further studies of the physiological role of tubulin acetylation. Immunofluorescence microscopy is a useful method for revealing the intracellular localization and eventual changes of acetylated tubulin, while the quantification method described here is a useful complement for measuring the magnitude of the phenomenon.

\section{Acknowledgments}

We thank Dr. S. Anderson for English editing. This study was supported by the Agencia Nacional de Promoción Científica y Tecnológica de la Secretaría de Ciencia y Tecnología del Ministerio de Cultura y Educación (Préstamo BID - PICT 1439), the Consejo Nacional de Investigaciones Científicas y Técnicas (CONICET), and the Secretaría de Ciencia y Técnica de la Universidad Nacional de Córdoba.

The authors declare no conflict of interest. 


\section{References}

Akella JS, Wloga D, Kim J, Starostina NG, Lyons-Abbott S, Morrissette NS, Dougan ST, Kipreos ET, Gaertig J. 2010. MEC-17 is an alpha-tubulin acetyltransferase. Nature 467 (7312):218-22.

Alonso AC, Nunez-Fernandez M, Beltramo DM, Casale CH, Barra HS. 1998. Na+,K+-ATPase was found to be the membrane component responsible for the hydrophobic behavior of the brain membrane tubulin. Biochem Biophys Res Commun 253(3):824-7.

Bradford MM. 1976. A rapid and sensitive method for the quantitation of microgram quantities of protein utilizing the principle of protein-dye binding. Anal Biochem 72:248-54.

Carbajal A, Chesta ME, Bisig CG, Arce CA. 2013. A novel method for purification of polymerizable tubulin with a high content of the acetylated isotype. Biochem J.449(3):643-8.

Casale $\mathrm{CH}$, Alonso AD, Barra HS. 2001. Brain plasma membrane $\mathrm{Na}+, \mathrm{K}_{+}-\mathrm{ATP}$ ase is inhibited by acetylated tubulin. Mol Cell Biochem 216(1-2):85-92.

Casale $\mathrm{CH}$, Previtali G, Barra HS. 2003. Involvement of acetylated tubulin in the regulation of $\mathrm{Na}+\mathrm{K}+$-ATPase activity in cultured astrocytes. FEBS Lett 534(1-3):115-8.

Casale CH, Previtali G, Serafino JJ, Arce CA, Barra HS. 2005. Regulation of acetylated tubulin/Na+,K+-ATPase interaction by L-glutamate in non-neural cells: involvement of microtubules. Biochim Biophys Acta 1721(1-3):185-92.

Hubbert C, Guardiola A, Shao R, Kawaguchi Y, Ito A, Nixon A, Yoshida M, Wang XF, Yao TP. 2002. HDAC6 is a microtubule-associated deacetylase. Nature 417(6887):455-8.

Janke C, Bulinski JC. 2011. Post-translational regulation of the microtubule cytoskeleton: mechanisms and functions. Nat Rev Mol Cell Biol 12(12):773-86.

Laemmli UK. 1970. Cleavage of structural proteins during the assembly of the head ofbacteriophage T4. Nature 227:680-685

Li L, Wei D, Wang Q, Pan J, Liu R, Zhang X, Bao L. 2012. MEC-17 deficiency leads to reduced alpha-tubulin acetylation and impaired migration of cortical neurons. J Neurosci 32(37):1267383.

North BJ, Marshall BL, Borra MT, Denu JM, Verdin E. 2003. The human Sir2 ortholog, SIRT2, is an NAD+-dependent tubulin deacetylase. Mol Cell 11(2):437-44.

Perdiz D, Mackeh R, Pous C, Baillet A. 2011. The ins and outs of tubulin acetylation: more than just a post-translational modification? Cell Signal 23(5):763-71.

Piperno G, Fuller MT. 1985. Monoclonal antibodies specific for an acetylated form of alpha-tubulin recognize the antigen in cilia and flagella from a variety of organisms. J Cell Biol 101(6):208594. 
Santander VS, Bisig CG, Purro SA, Casale CH, Arce CA, Barra HS. 2006. Tubulin must be acetylated in order to form a complex with membrane $\mathrm{Na}(+), \mathrm{K}(+)$-ATPase and to inhibit its enzyme activity. Mol Cell Biochem 291(1-2):167-74.

Shida T, Cueva JG, Xu Z, Goodman MB, Nachury MV. 2010. The major alpha-tubulin K40 acetyltransferase alphaTAT1 promotes rapid ciliogenesis and efficient mechanosensation. Proc Natl Acad Sci USA 107(50):21517-22.

Towbin H, Staehelin T, Gordon J. 1979. Electrophoretic transfer of proteins frompolyacrylamide gels to nitrocellulose sheets: procedure and some applications.Proc Natl Acad Sci USA 76:4350-4354.

Tran AD, Marmo TP, Salam AA, Che S, Finkelstein E, Kabarriti R, Xenias HS, Mazitschek R, Hubbert C, Kawaguchi $Y$ and others. 2007. HDAC6 deacetylation of tubulin modulates dynamics of cellular adhesions. J Cell Sci 120(Pt 8):1469-79.

Wessel D and Flügge UI. 1984. A method for the quantitative recovery of protein in dilute solution in the presence of detergents and lipids. Anal Biochem138:141-3.

Zampar GG, Chesta ME, Carbajal A, Chanaday NL, Díaz NM, Casale CH, Arce CA. 2009. Acetylated tubulin associates with the fifth cytoplasmic domain of $\mathrm{Na}^{+}, \mathrm{K}^{+}$-ATPase: possible anchorage site of microtubules to the plasma membrane. Biochem J 422:129-137.

Zhang Y, Li N, Caron C, Matthias G, Hess D, Khochbin S, Matthias P. 2003. HDAC-6 interacts with and deacetylates tubulin and microtubules in vivo. EMBO J 22(5):1168-79. 


\section{Figure Legends}

Fig. 1. Chemical acetylation of tubulin. (A) Two types of tubulin preparation were chemically acetylated: a $\mathrm{SN}_{1}$ fraction (obtained in the absence of TSA) and an immunopurified AcTubulin preparation (see Materials and Methods). The 2 preparations were chemically acetylated (+) or not (-) and subjected to Western blot analysis and staining with anti-AcTubulin mAb 6-11B-1. Following chemical acetylation, the AcTubulin band in both cases showed a lower electrophoretic mobility (arrow) in comparison with the preparation that was not chemically acetylated (arrowhead). (B) A microtubule protein $(3 \mathrm{mg} / \mathrm{ml}$ ) preparation purified by 1 cycle of assembly/disassembly was incubated for $20 \mathrm{~min}$ at room temperature in the presence of $1 \%$ acetic anhydride, $\mathrm{pH} 9$. An aliquot was removed for subsequent analysis (Western blotting with mAb 6-11B-1), and the mixture was acetylated again under the same conditions. Another aliquot was removed, and a third acetylation step was performed. (C) Various protein amounts from each of the 3 acetylation steps as above were immunoblotted and stained with mAb 6-11B-1. AcTubulin bands from 3 independent experiments were scanned and the optical density values (mean \pm S.D.)are shown.

\section{Fig. 2. Immunoreactivity of mAb 6-11B-1 with proteins of a crude brain extract following} chemical acetylation. The soluble extract of a rat brain homogenate was acetylated with acetic anhydride and subjected to SDS-PAGE and immunoblotting with mAb 6-11B-1. (A) Chromatogram of the soluble extract stained with Coomassie Blue and the corresponding densitogram showing that tubulin (arrowhead) accounts for $16 \%$ of total proteins. (B) Immunoblot stained with mAb 6$11 \mathrm{~B}-1$ and the corresponding densitogram. Staining that coincides with the tubulin band accounted for $94 \%$ of the total immunoreactivity.

Fig. 3. Standard curve for AcTubulin. An AcTubulin-enriched preparation (microtubule protein preparation purified by 1 cycle) was chemically acetylated to obtain $100 \%$ AcTubulin. In this preparation, tubulin representedapproximately $55 \%$ of total proteins (results not shown). Various amounts of protein were subjected to Western blotting and visualized for AcTubulin. The bands were scanned and optical density values were calculated as a function of protein amount. The values are presented as the means \pm S.D. from quadruplicate determinations.

Fig. 4. Quantification of AcTubulin in partially purified preparations. An AcTubulin-enriched preparation (microtubule protein purified by 1 cycle; $2.5 \mathrm{mg} / \mathrm{ml}$ ) was mixed in various proportions with an AcTubulin-depleted preparation (microtubule protein purified by 1 cycle; $2.5 \mathrm{mg} / \mathrm{ml}$ ). The resulting mixtures consisted of $7.5,27.5$, and $60 \%$ AcTubulin. Aliquots of each preparation (100 $\mu$ l) 
were used to determine AcTubulin content by our quantification method (see Materials and Methods). The values shown are the means \pm S.D. from 3 independent experiments.

Fig. 5. Quantification of AcTubulin in cultured cells. (A) Effects of the presence of the detergents SDS and Triton X-100 on chemical acetylation. Aliquots of a soluble tubulin preparation $\left(\mathrm{SN}_{1}\right.$, obtained in the absence of TSA), after the addition of SDS or Triton X-100 (final concentration $0 \%, 1 \%$, or $3 \%$ in both cases) were chemically acetylated and subjected to Western blotting and subsequent staining for AcTubulin (AcTub). (B) CHO, COS, and CAD cells were cultured in 10-mm dishes and treated with (+TSA) or without (-TSA) $5 \mu \mathrm{M}$ TSA for $6 \mathrm{~h}$, and the AcTubulin content was measured as described in Materials and Methods. The values shown are the means \pm S.D. from 4 independent experiments. (C) The same cell types as in (B) were grown on coverslips and processed in the same way (+TSA or -TSA; $6 \mathrm{~h}$ ), and acetylated microtubules were visualized by immunofluorescence. Scale bar $=20 \mu \mathrm{m}$.

Fig. 6. Quantification of AcTubulin in $\mathrm{CHO}$ and $\mathrm{COS}$ cells before and after taxol treatment. (A) Cells were grown on coverslips and treated with $5 \mu \mathrm{M}$ taxol for 0,2 , or $6 \mathrm{~h}$, and microtubules were visualized by immunofluorescence microscopy using anti-AcTubulin mAb 6-11B-1. Scale bar $=20 \mu \mathrm{m}$. (B) Cells were grown in 10-cm dishes and treated as in (A) in parallel experiments. The AcTubulin content was measured by the chemical acetylation method as described in Materials and Methods. The values shown are the means \pm S.D. from 3 independent experiments.

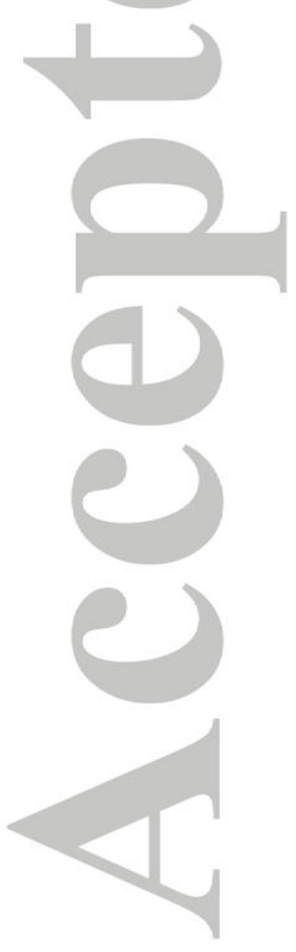



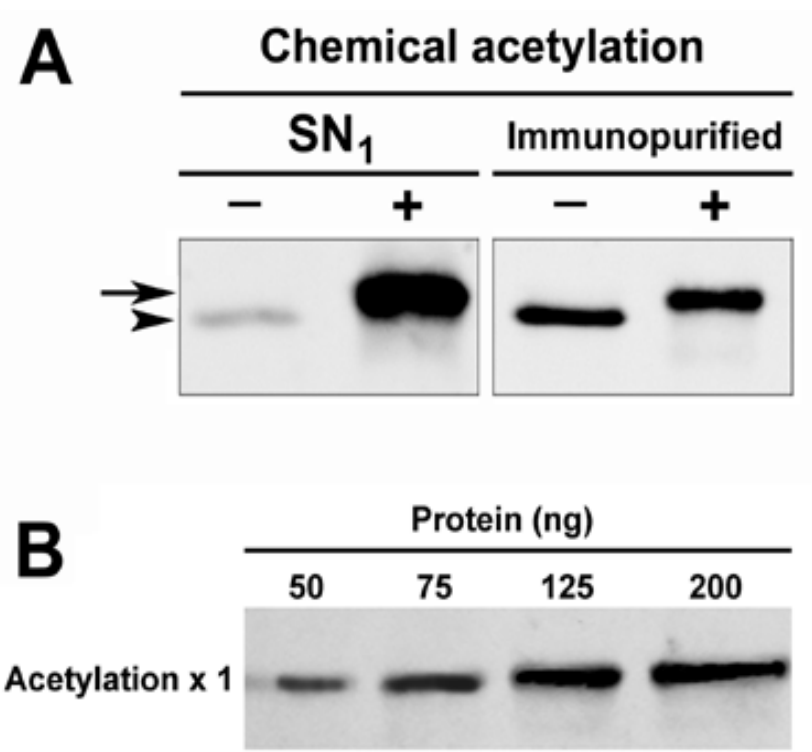

Acetylation $\times 2$

Acetylation x 3

C

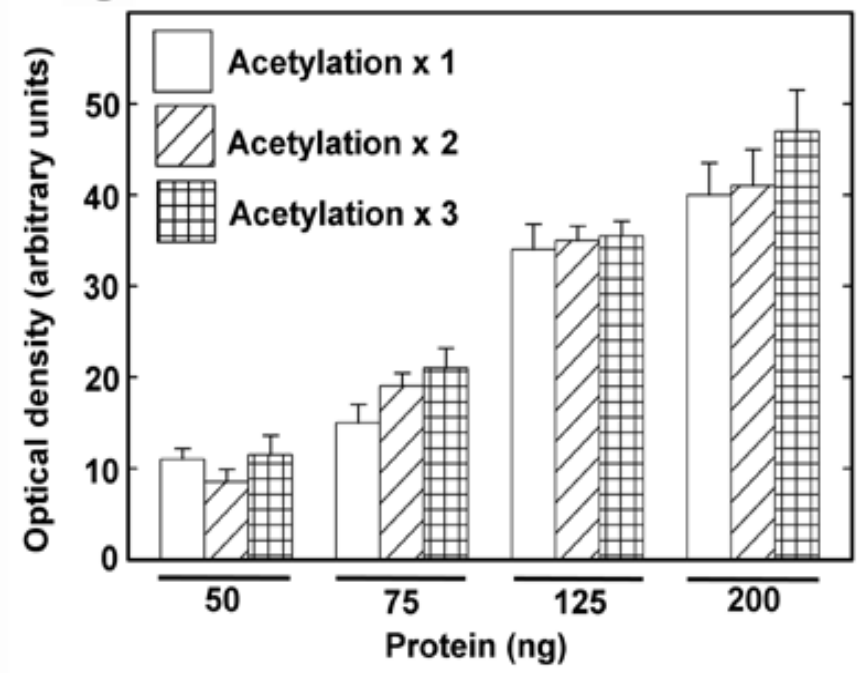

Fin. 1 


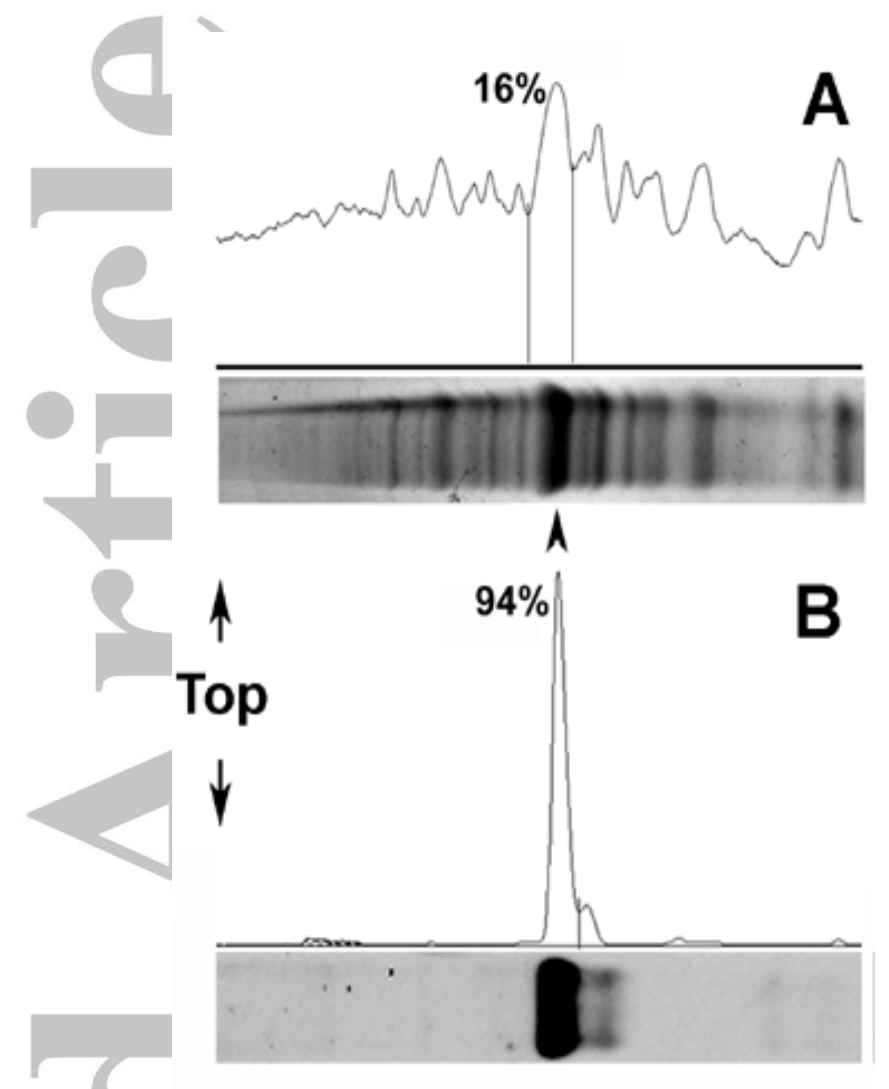

Fig. 2

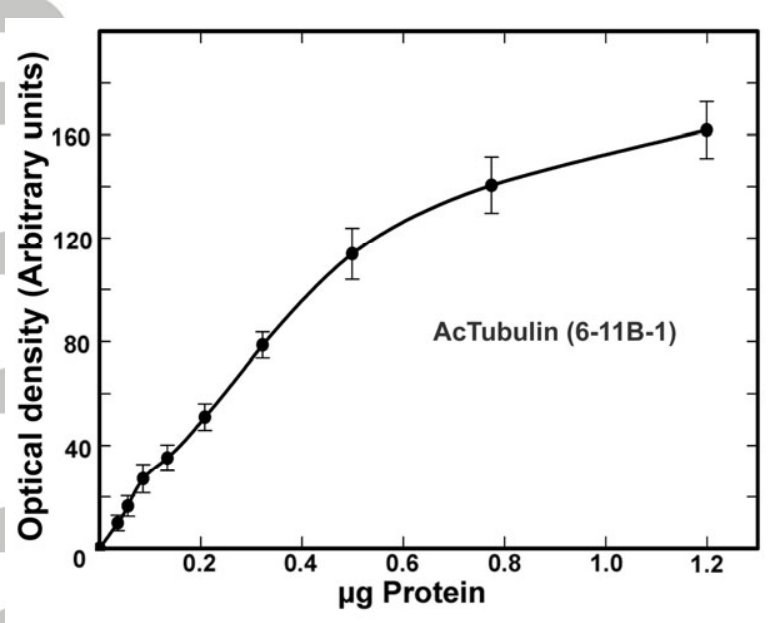

Fig. 3 


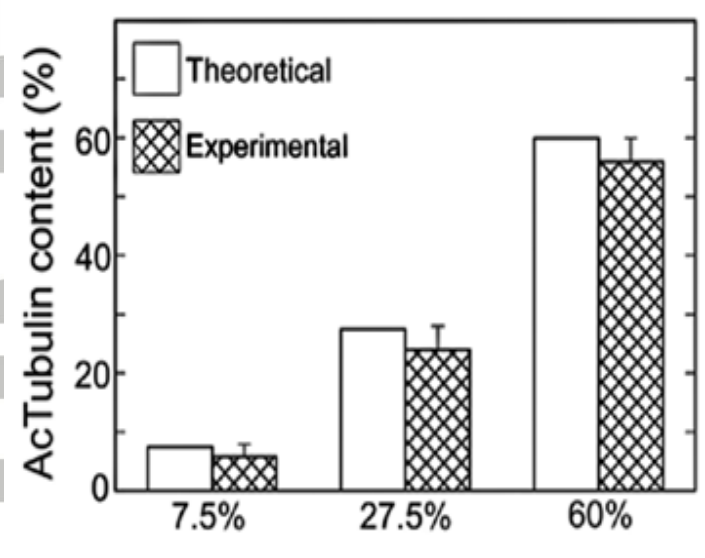

Fig. 4
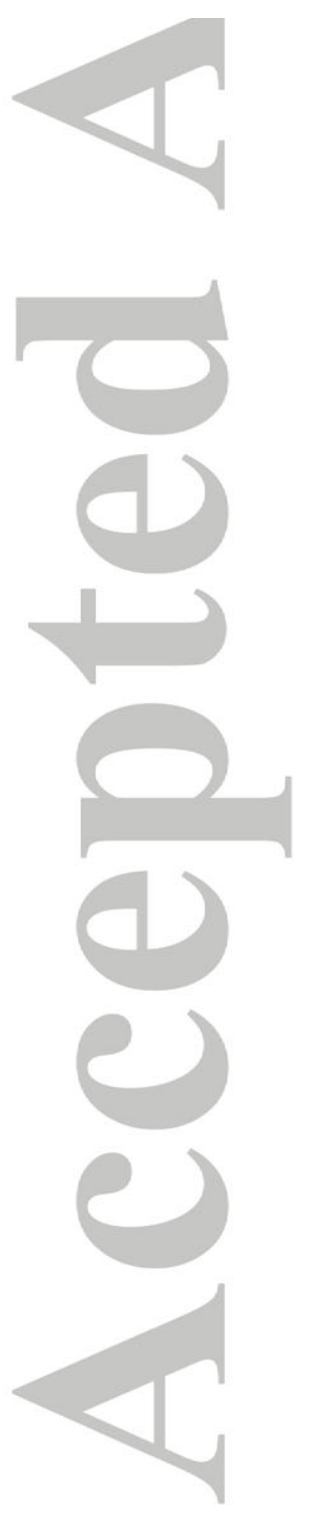


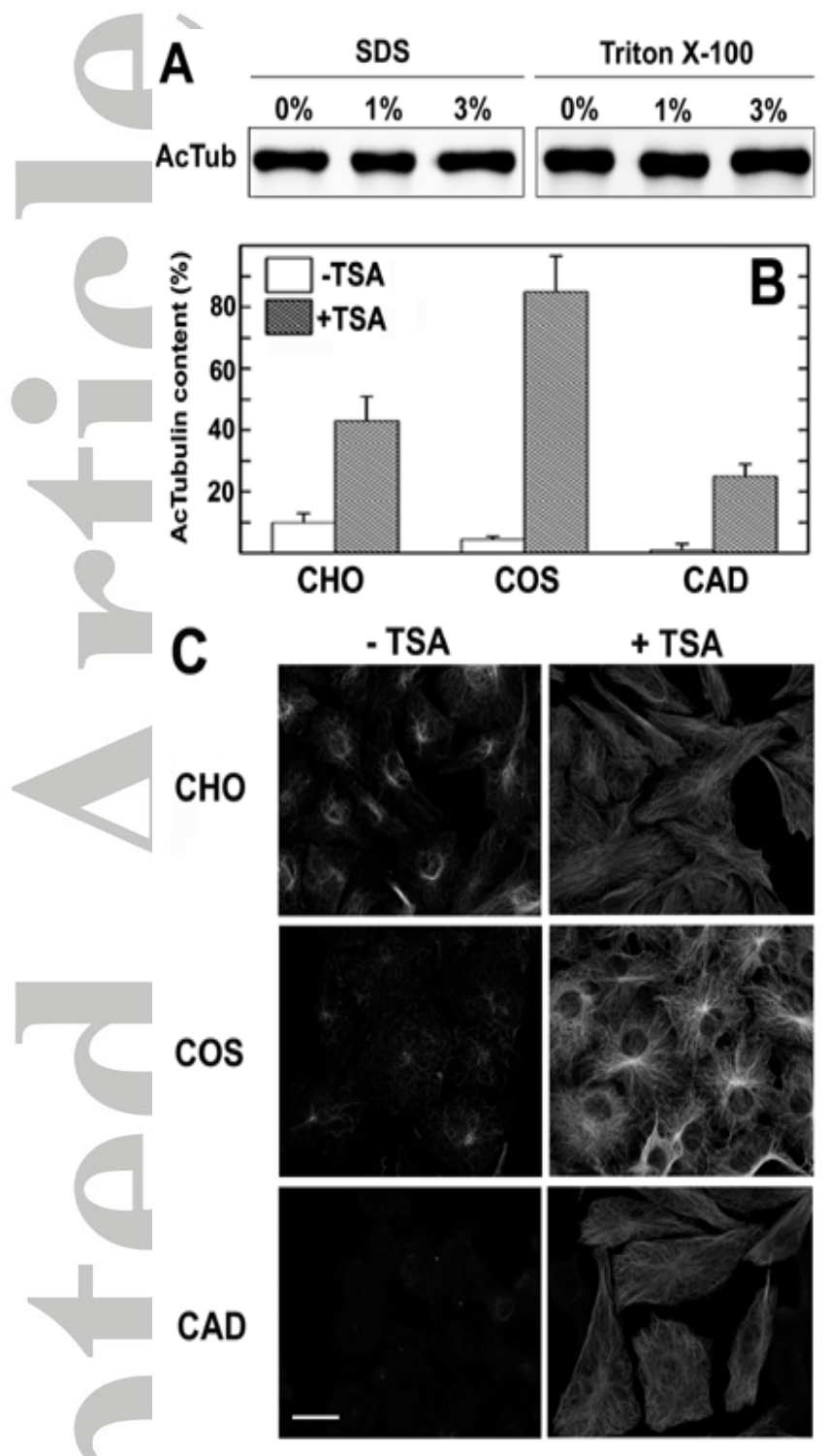

Fig. 5 

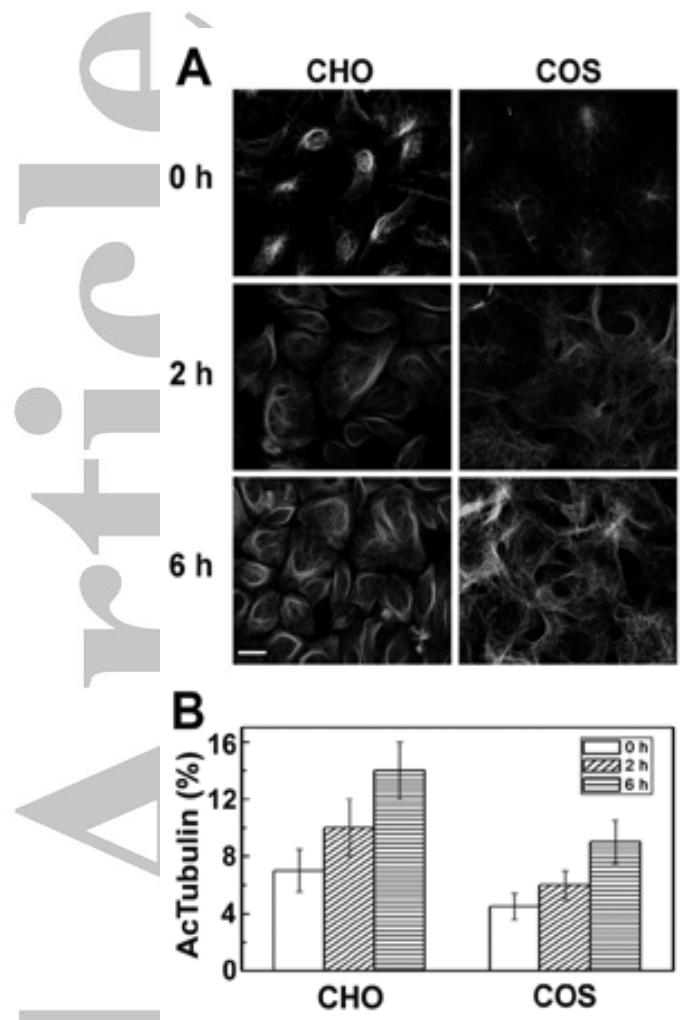

Fig. 6

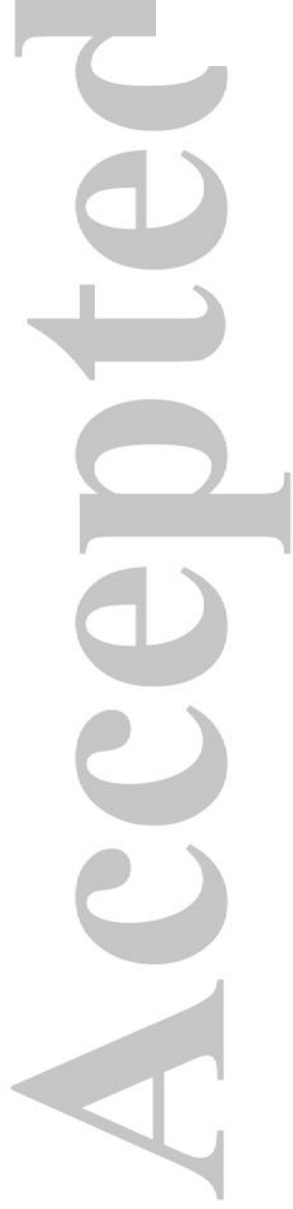

